\title{
Anterior Segment Biometry Using Spectral Domain Optical Coherence Tomography
}

\author{
AMIRA E.Z. EL-HAYES, M.Sc.*; MOUSTAFA K. NASSAR, M.D.** and MOATAZ F. EL-SAWY, M.D.* \\ The Department of Ophthalmology, Faculty of Medicine, Cairo* and Menoufia** Universities
}

\begin{abstract}
Background: AS-OCT allows a non-contact examination with high resolution imaging of the anterior segment of the eye of human. It enables assessment and documentation of the condition of the eye's anterior segment.

Aim of Study: Evaluation of Anterior Segment Optical Coherence Tomography (AS-OCT) in quantitative analysis of the anterior segment of the eye. Analysis of association between Central Corneal Thickness (CCT), Corneal Epithelial Thickness (CET) and corneal radius of curvature (CC) measured by OCT in relation to other parameters; age, sex, refraction and Intra Ocular Pressure (IOP).
\end{abstract}

Patients and Methods: The present study included 100 normal eye of 100 hundred patients aged from 20:60 years. CCT, CET and radius of CC were measured using anterior segment Spectral Domain Optical Coherence Tomography (SD-OCT) (3D OCT-2000 (Topcon Corp., Tokyo, Japan)) IOP was measured using Goldman applanation tonometer. Measurements of refractive status were detected by autorefractor and then confirmed by retinoscopy and spherical equivalent was calculated of astigmatic patients.

Results: Total number of 100 eye were evaluated for the study. 34 eyes were emmetrope, 34 eyes were myopes and 32 eyes were hypermetropics. The CCT average was 541.62 (SD \pm 21.11 ). This study showed no statistically significant difference between CCT in myopes, hypermetropes and emmetropes). Mean IOP was $15.65 \mathrm{mmHg}$ (SD \pm 1.56 ). The correlation between IOP and CCT was highly significant $(r=$ $0.867 ; p<0.001$ ). The CET average was 54.80 (SD \pm 2.68 ). The study has shown the positive relation between CET and CCT. The mean radii of corneal curvature was vertically 7.61 ( $\mathrm{SD} \pm 0.27$ ) and horizontally was 7.61 (SD \pm 0.25 ). We found a statistically relation between error of refraction and corneal radius of curvature. Eyes with more myopic refractive error tend to have steeper corneas with less radii of curvature on controversy with hypermetropic eyes. No correlation between age or sex to all the above.

Conclusion: This study has shown that CCT has no correlation with degree of refractive error. Whereas there is significant correlation between CCT and IOP and CET as well. The study also has shown that there were no associations between corneal radius of curvature and IOP. However, myopic

Correspondence to: Dr. Amira E.Z. El-Hayes, The Department of Ophthalmology, Faculty of Medicine, Cairo University eyes shows tendency for smaller radii of curvature whereas in hypermetropic ones the radii of curvature tend to be longer. There was no significant relation between age and sex and any parameter of the study. Our findings highlight the value of spectral domain AS-OCT measurements as a standard tool in anterior segment analysis.

Key Words: Optical coherence tomography-Central corneal thickness - Corneal epithelial thickness - Corneal radius of curvature - Myopia - HypermetropiaEmmetropia.

\section{Introduction}

THE prevalence of non-invasive methods that have the ability of in situ visualization of tissue became of particular importance in ophthalmology because of the key information provided by them regarding the physiology and the diseases related to the eye. The structures of the anterior segment can be analyzed using many ultrasonic or optical methods. OCT is among these methods which became used increasingly due to its ability for providing a non-contact scans to the anterior segment of the eye. This makes the examination comfortable, safe and fast. In addition to making a high transverse and axial spatial resolution on the order of not much dozen of micrometers [1-3]. This includes the option to determine central corneal thickness and also corneal epithelial thickness in addition to anterior corneal radius of curvature $[4,5]$.

The cornea is considered the most important structure of refraction for the eye. The shape of the cornea and the relative large difference between its refractive index and that of the air explains the corneal refractive power [6]. Corneal parameters measurements are very important in both diagnosis and management of many ocular pathological conditions that may cause bad visual outcome such as glaucoma, keratoconus and diabetic manifestations that lead to change in the architecture of the cornea [7]. 
CCT is an important indicator of cornea health. Interest in CCT measurement has greatly increased because its effect on IOP measurement. CCT itself affects the accuracy of measurement of IOP [8] It's a fact that thin corneas lead to underestimation of IOP whereas thick ones result in its overestimation. So because of the relationship between IOP and CCT, decreased CCT values might result in delayed diagnosis and management of glaucoma [9]. In addition to all that in the era of refractive surgery, CCT values became marvelously important to evaluate the patients pre-operatively because they affect the decision whether not or to do the operation, type of the recommended procedure and rate of the complications that might occur postoperatively [10]

The human corneal surface is covered by the corneal epithelium, where it plays an important role in protecting and maintaining the optimum optical quality. It cannot be ignored that the corneal epithelium contributes greatly to the corneal refractive power and hence to the ocular refraction. Some diseases like keratoconus alter the thickness of the epithelium to reduce the irregularity of the corneal surface [11]. Contact lens wearers can also show epithelial thickness abnormalities as they might exhibit epithelium wrapping more likely. This will also lead to incorrect evaluation of their real refraction [12]. So analyzing the CET separately is important for early detection of the disease in an earlier stage [11].

Anterior Corneal Curvature (ACC) is related to the frontal surface of the cornea and is one of the valuable measurements used to make optical properties of the cornea more characteristic. In clinical practice, vertical and horizontal anterior corneal curvatures are both measured. The average cornea has a larger radius in the horizontal meridian in comparison to the vertical meridian, which cause higher percentage of with-the-rule astigmatism in young adults [13]. Anterior curvature expressed in radii (millimeters typically) is of importance for fitting and management of contact lens, analysis of ocular aberration, refractive surgery of cornea in addition to diagnoses and treatment of corneal pathological cases like keratoconus [14,15] .

The aim of the study is firstly to highlight the value of the SD-OCT measurements as a standard tool in anterior segment analysis. The second goal of this study is to determine range of distribution, correlation of ocular parameters (CCT, CE, horizontal and vertical corneal radii of curvature) in a number of patients of different age and sex with abroad range of refractive error and IOP.

\section{Patients and Methods}

The study was designed as a cross-sectional, observational study, the participants were chosen by simple random sampling.

The study was carried out in accordance with the ethical standards stated in the declaration of Helsinki and was approved by the Ethical Committee of Menoufia Medical School. The study protocol was explained to the patients and all patients were provided a written informed consent.

The study was conducted at a special eye center at Cairo from February 2017 to September 2017. This study was conducted on 100 eyes of 100 volunteers 52 males and 48 females ranging from (20-60) year-old. The study will include healthy individuals including 34 myopic, 34 emmetropic and 32 hypermetropic individuals.

\section{Inclusion criteria:}

Same age group (20:60 year-old) healthy eyes of healthy volunteers will be included after assestment of their Best Corrected Visual Acuity (BCVA) and slit lamp stereo microscopy.

\section{Exclusion criteria:}

\section{Exclusion criteria have been as follows:}

Cornea opacity of any type or degree, preexisting ocular pathology.

Having any other ocular disease (eg: Glaucoma, uveitis, ocular hypertension).

Eyes with previous history of previous intraocular or refractive surgery or trauma.

Having any type of previous retinal treatment (e.g.: Macular laser photo coagulation, vitrectomy, and/or intravitreal steroid).

Participants who received topical or systemic medication that could affect the iris or angle configuration at the time of the study (cholinergics or anticholinergics, adrenergic agonists or antagonists, serotonin, norepinephrine, and dopamine releasers or precursors or reuptake inhibitors, monoamine oxydase inhibitors, opioid agonists or antagonists, and histamine receptor antagonists) were excluded.

Subjects wearing contact lenses were excluded as this might affect corneal thickness.

\section{Examination:}

The medical histories of the patients were obtained from the volunteer. A complete ophthalmologic examination including; best-corrected visual acuity by decimal chart. 
The anterior segment of each eye was carefully examined by slit lamp for corneal opacities or abnormalities, depth of anterior chamber, iris color and pattern, regularity and uveitis, lens position.

Fundus examination by indirect ophthalmoscope and 90D lens for examination of the macula, optic disc, retinal vessels, retinal background.

IOP was measured using Goldman applanation tonometer. Three averaged measurements were obtained per eye.

Measurements of refractive status were detected by autorefractor (Nidek AR-310 Auto refractometer) and then confirmed by retinoscopy and spherical equivalent was calculated of astigmatic patients.

- Using anterior Segment Spectral Domain Optical Coherence Tomography (SD-OCT) (3D OCT2000 (Topcon Corp., Tokyo, Japan)); central corneal thickness, corneal epithelial thickness and corneal radii of curvature both horizontally and vertically were measured. The subject was asked to look at the internal fixation target and. Three scans were obtained for each tested eye and the mean of these scans was used for the analysis.

The cornea was imaged with the anterior segment mode of the 3D OCT-2000 (Topcon Corp., Tokyo, Japan). Automated calculation of corneal curvature, Central Corneal Thickness (CCT) and corneal epithelial thickness CET with the integrated software was performed and all OCT images were checked for correct identification of the corneal surface. Quality of OCT scans were graded in a four categories: "High", "medium", "acceptable", and "insufficient". Mean curvature of the corneal radius was computed.

Fundus photographs of the macula and optic nerve head were obtained from all participants and images were evaluated by two independent ophthalmologists.

\section{Statistical analysis:}

The data collected was tabulated and analyzed by SPSS statistical package Version 20. (SPSS Inc., Chicago, IL, USA). Two types of statistical analysis were done:

A- Descriptive statistics were expressed in: Number (No), percentage (\%) mean (X) and Standard Deviation (SD).

B-Analytic statistics: Pearson correlation was used to show correlation between two continuous normally distributed variables while Spearman correlation was used for not normally distributed ones.
- Repeated measures ANOVA (analysis of the variance) test has been used for the comparison of quantitative variables between more than two consecutive measures in the same group of normally distributed data and Friedman test has been used for comparison of quantitative variables between more than two consecutive measures in the same group of not-normally distributed data with LSD test as post Hoc test.

- $p$-value of $<0.05$ was considered statistically significant.

\section{Results}

This study included 100 eyes of 100 individual with a mean age of $40.82 \pm 11.30$ years (range, 2060 years), the patients; gender were $52(52.0 \%)$ male and $48(48.0 \%)$ female. Among the studied eyes 34 eyes were myopic, 24 emmetropic and 32 hypermetropic as shown in (Table 1).

The mean IOP was $15.65 \pm 1.56 \mathrm{~mm} \mathrm{Hg}$ (Table 1).

Table (1): Distribution of the studied cases according to different parameters $(n=100)$.

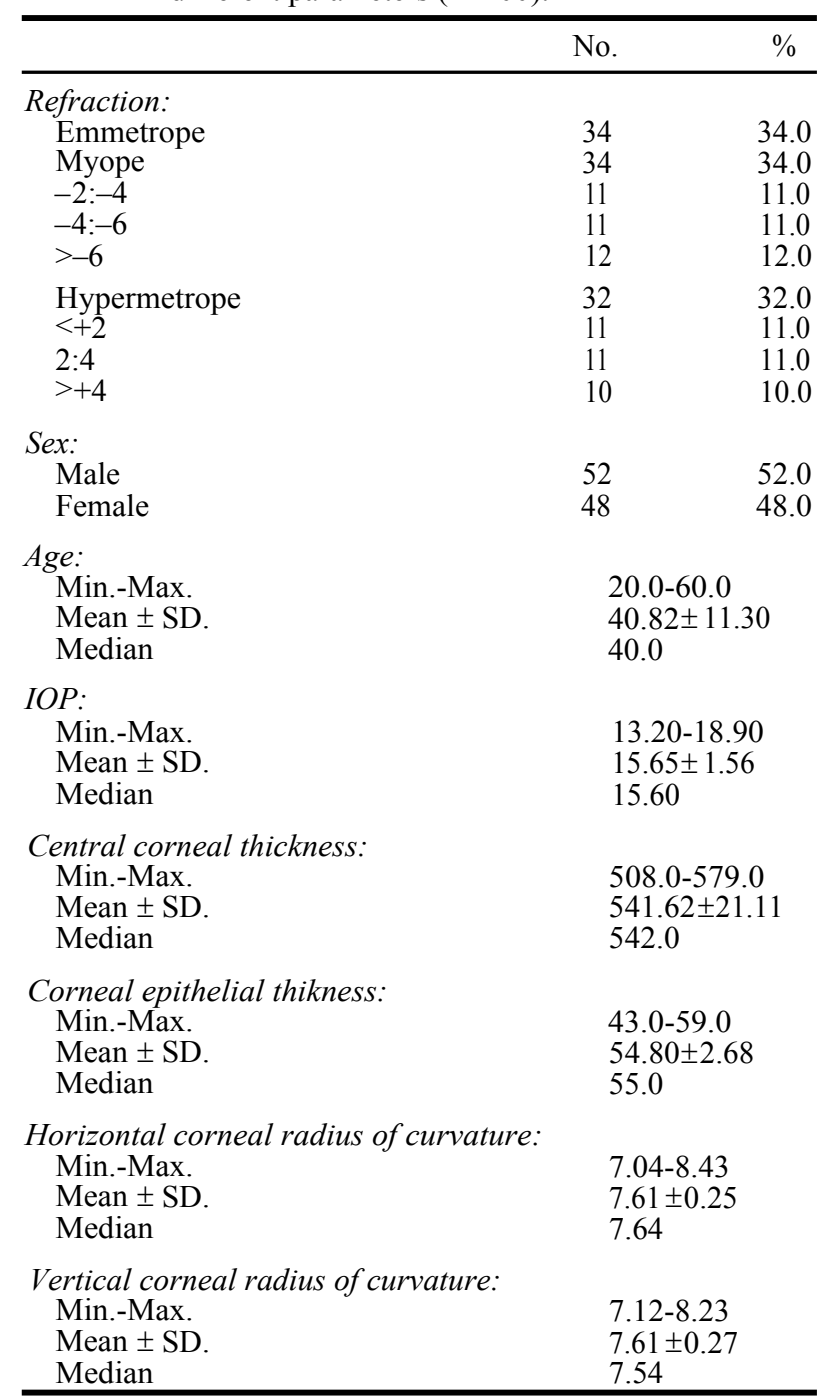


Considering all eyes together, mean CCT was $541.62 \pm 21.11 \mathrm{~m}$ (Table 1). [Mean SD in males it was $541.94 \pm 22.53$ and in females $541.27 \pm 19.68$ (Table 4)]. This study showed no statistically difference in myopic $(542.79 \pm 20.02)$, emmetropic $(540.09 \pm 22.29)$ or hypermetropic $(542.0 \pm 21.52)$ $(\mathrm{f}=0.145, p=0.865)$ (Table 2$)$. The study also showed positive correlation between CCT and IOP $(r=0.867, p<0.001)$ (Table 3$)$ and also positive correlation between CCT and CET ( $r=0.516$, $p<0.001$ ) (Table 5).

Regarding CET; average was $54.80 \pm 2.68$ (Table 1). [Mean SD was $54.75 \pm 2.44$ in males and $54.85 \pm 2.94$ in females (Table 4)]. The study showed no correlation between CET and refractive error ( $\mathrm{f}=0.165, p=0.848)$ (Table 2). It showed that there is also positive correlation between CET and IOP $(r=0,490, p<0,001)$ (Table 3).

About corneal radii of curvature the study showed that average horizontal corneal radius of curvature was $7.61 \pm 0.25 \mathrm{~mm}$ while mean vertical corneal radius of curvature was $7.61 \pm 0.27 \mathrm{~mm}$ (Table 1). This study has showed the correlation between the corneal radius of curvature and refractive state of the eye $(p<0.001)$ (Table 2$)$ as it was found that myopes $(\mathrm{H} 7.53 \pm 0.19 \mathrm{~mm}-\mathrm{V} 7.50 \pm 0.18$ $\mathrm{mm}$ ) tend to have steeper corneas meaning shorter radius of curvature followed by the emmetropes $(\mathrm{H} 7.52 \pm 0.23 \mathrm{~mm}-\mathrm{V} 7.50 \pm 0.21 \mathrm{~mm})$ and lastly the hypermetropes ( $\mathrm{H} .80 \pm 0.23 \mathrm{~mm}-\mathrm{V} 7.84 \pm 0.28 \mathrm{~mm}$ ) whose corneas tend to be flatter with longer radius of curvature (Table 2). On the other hand there was no correlation between corneal radius of curvature and IOP (H $r=-0.094, p=0.351-\mathrm{V} r=-0.060$, $p=0.556)$ (Table 3$)$.

This study showed what no association between corneal radius of curvature and CCT or CET (Table $5)$.

Regarding anthropometric characteristics of the study sample, age and gender were not associated with CCT, CET or corneal radii of curvature (Tables 3,4).

Table (2): Comparison between the different studied groups according to different parameters.

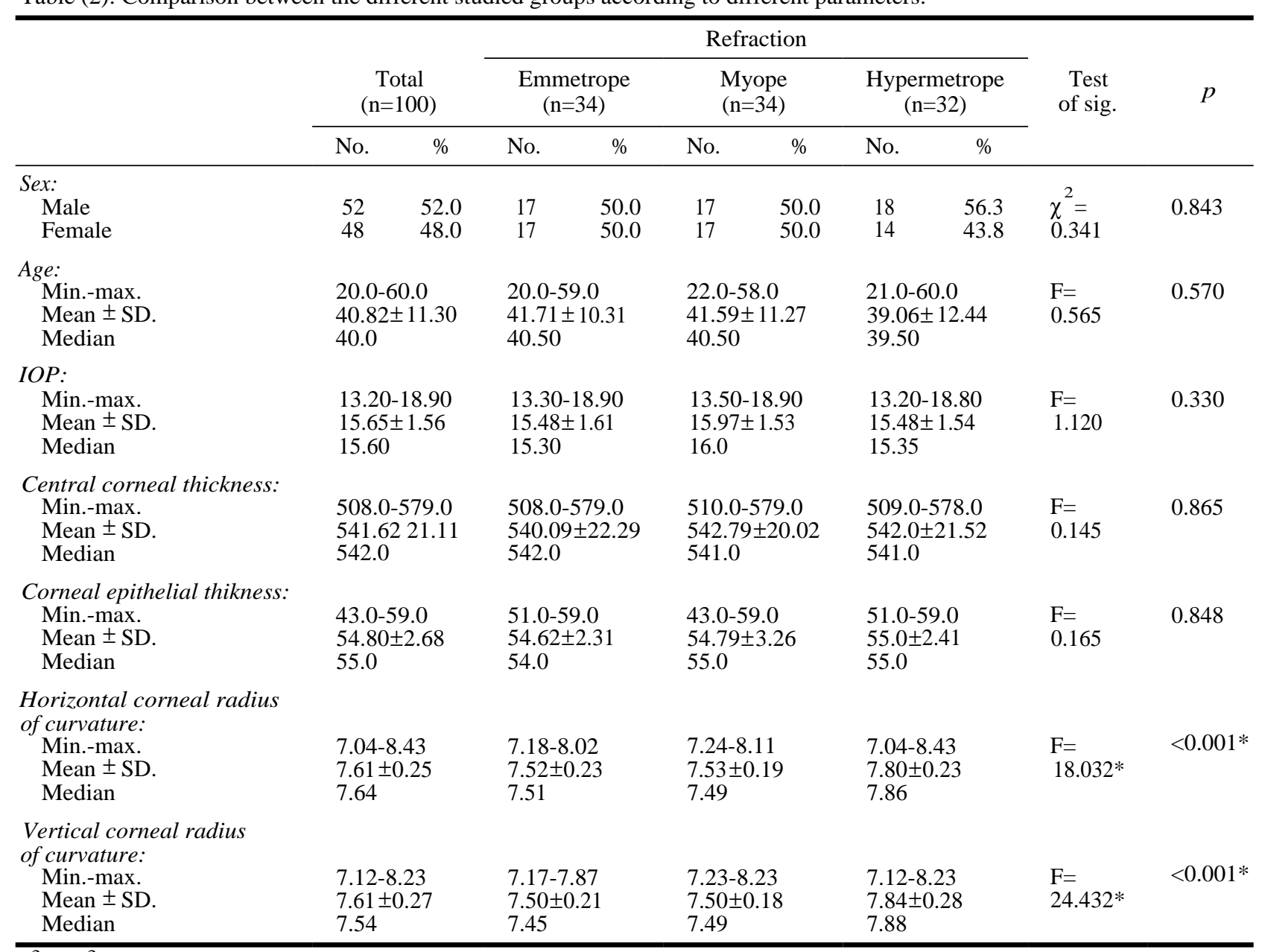

$\chi^{2}, p: \chi^{2}$ and $p$-values for Chi square test for comparing between the different groups.

$\mathrm{F}, p: \mathrm{F}$ and $p$-values for ANOVA test for comparing between the different groups.

$* \quad$ : Statistically significant at $p \leq 0.05$. 
Table (3): Correlation between different parameters in total sample $(\mathrm{n}=100)$.

\begin{tabular}{|c|c|c|c|c|}
\hline & \multicolumn{2}{|c|}{ Age } & \multicolumn{2}{|c|}{ IOP } \\
\hline & $r$ & $p$ & $r$ & $p$ \\
\hline - Central corneal thikness & 0.104 & 0.303 & $0.867^{*}$ & $<0.001 *$ \\
\hline - Corneal epithelial thikness & 0.022 & 0.824 & $0.490^{*}$ & $<0.001 *$ \\
\hline - Horizontal corneal radius of curvature & 0.003 & 0.977 & -0.094 & 0.351 \\
\hline - Vertical corneal radius of curvature & 0.050 & 0.623 & -0.060 & 0.556 \\
\hline
\end{tabular}

$r$ : Pearson coefficient. $\quad$ *: Statistically significant at $p \leq 0.05$.

Table (4): Relation between sex and different parameters in total sample $(n=100)$.

\begin{tabular}{|c|c|c|c|c|}
\hline & \multicolumn{2}{|c|}{ Sex } & \multirow[b]{2}{*}{$t$} & \multirow[b]{2}{*}{$p$} \\
\hline & $\begin{array}{l}\text { Male } \\
(\mathrm{n}=52)\end{array}$ & $\begin{array}{c}\text { Female } \\
(\mathrm{n}=48)\end{array}$ & & \\
\hline \multicolumn{5}{|c|}{ Central corneal thickness: } \\
\hline Min.-max. & $508.0-579.0$ & $508.0-579.0$ & 0.158 & 0.875 \\
\hline Mean \pm SD. & $541.94 \pm 22.53$ & $541.27 \pm 19.68$ & & \\
\hline Median & 541.0 & 542.0 & & \\
\hline \multicolumn{5}{|c|}{ Corneal epithelial thikness: } \\
\hline Min.-max. & $51.0-59.0$ & $43.0-59.0$ & 0.193 & 0.847 \\
\hline Mean \pm SD & $54.75 \pm 2.44$ & $54.85 \pm 2.94$ & & \\
\hline Median & 54.0 & 55.0 & & \\
\hline \multicolumn{5}{|c|}{ Horizontal corneal radius of curvature: } \\
\hline Min.-max. & 7.04-7.98 & $7.19-8.43$ & 1.452 & 0.150 \\
\hline Mean \pm SD & $7.58 \pm 0.24$ & $7.65 \pm 0.26$ & & \\
\hline Median & 7.56 & 7.65 & & \\
\hline \multicolumn{5}{|c|}{ Vertical corneal radius of curvature: } \\
\hline Min.-max. & $7.12-8.22$ & $7.25-8.23$ & 0.431 & 0.667 \\
\hline Mean \pm SD & $7.60 \pm 0.29$ & $7.62 \pm 0.26$ & & \\
\hline Median & 7.55 & 7.54 & & \\
\hline
\end{tabular}

$t, p$ : $t$ and $p$-values for student $t$-test for association between sex and different parameters.

Table (5): Correlation between different parameters in total sample $(n=100)$.

\begin{tabular}{lcc}
\hline & $r$ & $p$ \\
\hline $\begin{array}{l}\text { Central corneal thickness vs. horizontal } \\
\text { corneal radius of curvature }\end{array}$ & 0.002 & 0.981 \\
- Central corneal thickness vs. vertical & 0.025 & 0.804 \\
$\begin{array}{l}\text { corneal radius of curvature } \\
\text { - Corneal epithelial thikness vs. horizontal } \\
\text { corneal radius of curvature }\end{array}$ & -0.010 & 0.920 \\
- Corneal epithelial thikness vs. vertical & -0.170 & 0.092 \\
$\begin{array}{l}\text { corneal radius of curvature } \\
\text { - Central corneal thickness vs. corneal } \\
\text { epithelial thikness }\end{array}$ & $0.516^{*}$ & $<0.001 *$ \\
\hline$r:$ Pearson coefficient. & $*$ : Statistically significant at $p \leq 0.05$.
\end{tabular}

\section{Discussion}

The anterior segment spectral domain OCT was designed to analyze the anterior segment of the eye. The high scan rate makes it possible to capture a large number of two-dimensional tomographic images within a limited time and then to generate a three-dimensional representation of the anterior segment. The high scan rate should also decrease motion artifacts. This study used SD-OCT for measurement of central corneal thickness, corneal epithelial thickness and corneal radii of curvature which makes it technically different to other studies where analyses were done by the usage of ultrasound pachymetry or Scheimpflug imaging. SDOCT measures accurately those parameters as reported by prior publications within the physical limitations of the method itself as determined by wavelength, optical system, and sensor characteristics [16].

So in our study our primary outcome was to assess the distribution of ocular parameters in healthy eyes. Significant scatter was observed between the metrics; despite this many statistically significant correlations were found. We have evaluated central corneal thickness, corneal epithelial thickness and corneal radii of curvature in healthy eyes and its relation to age, sex intraocular pressure and refractive state of the eye using Topcon 3D OCT-2000. 


\section{As regarding central corneal thickness:}

- We have demonstrated that the central corneal thickness measurements were independently associated with intraocular pressure. Previously published studies have yielded congruent findings using optical or ultrasound pachymetry and association with intraocular pressure $[\mathbf{1 7 , 1 8}]$.

- We have also found that there was no correlation between CCT and spherical equivalent refractive error.

In agreement with that results studies failed to reveal a significant correlation between CCT and refraction Zhang et al., [19] in 4439 Chinese, Chen et al., [20] 500 Taiwanese Chinese and Su et al., [21] 3239 Singaporean Malays, respectively. It seems that CCT was not correlated with refractive error in the studies mentioned above.

In contrast other studies showed; for myopic populations, thinner corneas were reported in 216 young adults with an averaged refractive error of - 4.17 diopters Chang et al., [22], whereas no correlation with the degree of myopia was found in 714 Singaporean Chinese with a mean refractive error of -5.3 diopters Fam et al., [23]. For normal populations, a significant correlation between CCT and refraction was demonstrated in 3021 Japanese Suzuki et al., [24]

- In this study we have found no correlation between $\mathrm{CCT}$ and corneal radius of curvature.

In agreement to our study, Iyamu and Eze [25] investigated the relationship between CCT and corneal radius of curvature in 95 Nigerian adults (56 males and 39 females) aged between 20 and 69 years no significant association was found between CCT and corneal radius of curvature. On the contrary to our study Sawada et al., [26] reported a positive correlation between CCT and corneal radius of curvature in Japanese subjects $(\mathrm{N}=3021)$ aged 40 years or older.

- In our study population consisting of a cohort of Caucasians with an age range from 20 to 60 years, central corneal thickness was not associated with age.

Upon comparing our findings to those published by other groups, it must be considered that our age range corresponds to the working age and that we have only included healthy eyes with the purpose of reporting physiological conditions, whereas many other studies have appeared with a much older starting age reaching into senility. Wolfs et al., [27] and Eysteinsson et al., [28] are studies with different age ranges did not find an association between central corneal thickness and age. In contrast, in other ethnicities and especially in persons aged 70 years and older, Chua et al., [29] reported a decrease of central corneal thickness with age. This indicates that central corneal thickness may gradually increase in the decades covered by our cohort, while over 70 years a decrease may be observed.

- The presnt study showed that gender has no significant effect on CCT.

In agreement with our study Durkin et al., [30] and Aghanian et al., [31] showed no difference between male and female sex according to CCT. On controversy other studies like Shimmyo et al., [32] reported that males had thicker corneas than females. Hahn et al., [33] found that the difference in CCT between the genders was only $4.611 \mathrm{~m}$, which is less than the mean interocular difference in CCT $(7.711 \mathrm{~m})$ for their normal subjects. Therefore, they concluded that the difference between men and women CCT was statistically but not clinically significant.

\section{As regarding corneal epithelial thickness:}

- In this study, we found that at the center of the cornea, the thickness of the corneal epithelium correlated significantly with total corneal thickness and tended to maintain a ratio of around $10.160 .6 \%$ to total corneal thickness. This value was not related to age, sex or refraction, so CCT seems to be an independent predictive factor for central thickness of the corneal epithelium.

In agreement with these results Dmitrii et al., [34] had revealed positive correlation between CCT and CET. On the other hand $\mathrm{Wu}$ et al., [35] reported a weak correlation between corneal epithelial thickness and total central corneal thickness. They found the correlation coefficient 0.12 in contrast to our study, which had showed a correlation coefficient between central epithelial thickness and central corneal thickness to be as 0.53 which is much higher than Wu et al.

- Our study also showed no association between CET and age, sex and refractive state of the eye. Tao et al., [36] did not find a relation between the CET and gender or age in 44 eyes from 22 people. Francoz et al., [37] didn't find variation of CET in normal adults less than 40 years old $(n=18)$ and older adults larger than 40 years old $(n=10)$. Reinstein et al., [38] revealed no significant relationship between CET and age or refraction in 56 subjects. 


\section{As regarding corneal radius of curvature:}

- This study showed that there is a correlation between the radius of $\mathrm{CC}$ and refractive state of the eye $(p<0.001)$ as it was found that myopes tend to have steeper corneas meaning shorter radius of curvature followed by the emmetropes and lastly the hypermetropes whose corneas tend to be flatter with longer radius of curvature.

In agreement with that Goh and Lam [39] and Lam et al., [40] reported that the average radius of curvature did not vary significantly with the refractive status; however, myopes tended to have steeper corneas, followed by the emmetropes and lastly, the hyperopes. A subsequent study by Osuobeni [41] found similar results. Hosny et al., [42] have explained this apparent contradiction by indicating that myopic eyes, which are long, have steeper or shorter radius of $\mathrm{CC}$ because, together with an increase in axial length, corneal steepening also occurs during the development of myopia.

- This study didn't establish any relationship between IOP and radius of CC.

In agreement with our study Orssengo \& Pye [43], using randomly sampled normal 925 right eyes, none of them had keratorefractive surgery, no association was found between the radius of $\mathrm{CC}$ and IOP. Another study, carried out using Goldman applanation tonometry on 87 patients, found a mean drop in IOP of $0.71 \mathrm{mmHg}$ per $10 \mu \mathrm{m}$ thinning of the cornea. Its authors suggested that a change in the radius of curvature of the cornea had at least some effect on IOP measurements Rosa et al., [44]

- In this study there was no association between age or sex to radius of $\mathrm{CC}$.

Tomlinson A [45] in his study he agreed with our study and demonstrated no relation between age and gender and radius of CC.

On the other hand Mohd-Ali et al., [46] reported that the radius of corneal curvature becomes shorter with increasing age, he also demonstrated that females had significantly shorter average radius of CC than males $(p<0.001)$. Whereas Lam et al., [40] in subjects aged 40 years and older reported that men have longer radius of $\mathrm{CC}$ than women of same age. He explained these differences because of various factors such as refractive errors such as higher degree of myopia in females resulting in steeper corneas.

\section{Conclusion:}

Our study highlights the value of anterior segment SD-OCT in assessment of anterior segment.
We evaluated associations of central corneal thickness corneal, epithelial thickness and radius of corneal curvature readings determined by SD-OCT in healthy eyes. As our study was explicitly focused on healthy eyes, this approach may be worthwhile for defining norm values for this specific technology. Analysis confirmed intraocular pressure and refractive error as ocular factors associated with our examined parameters. We also assisted the association of age and gender to our biometry.

\section{References}

1- IZATT J.A., HEE M.R., SWANSON E.A., et al.: Micrometer-scale resolution imaging of the anterior eye in vivo with optical coherence tomography. Arch. Ophthalmol., 112: 1584-9, 1994.

2- KOOP N., BRINKMANN R., LANKENAU E., FLACHE S., ENGELHARDT R. and BIRNGRUBER R.: Optical coherence tomography of the cornea and the anterior eye segment. Ophthalmologe, 94: 481-6, 1997.

3- HOERAUF H., SCHOLZ C., KOCH P., ENGELHARDT R., LAQUA H. and BIRNGRUBER R.: Transscleral optical coherence tomography: A new imaging method for the anterior segment of the eye. Arch. Ophthalmol., 120: 816-9, 2002.

4- KONSTANTOPOULOS A., HOSSAIN P. and ANDERSON D.F.: Recent advances in ophthalmic anterior segment imaging: A new era for ophthalmic diagnosis? $\mathrm{Br}$. J. Ophthalmol., 91: 551-7, 2007.

5- WOLFFSOHN J.S. and DAVIES L.N.: Advances in anterior segment imaging. Curr. Opin. Ophthalmol., 18: 32 8, 2007.

6- RUSKELL G.L. and BERGMANSON J.P.G.: Anatomy and physiology of the cornea and related structures. In: Phillip A.J., Speedwell L, eds. Contact Lenses. 5 th Ed. Oxford: ButterworthHeinemann, 2006.

7- WU R.Y., ZHENG Y.F., WONG Y.Y., CHEUNG C.Y.C., LOON S.C., CHAUHAN B.C. and AUNG T.: Relationship of central corneal thickness with optic disc parameters: The Singapore Malay Eye Study. Inv. Ophthalmol. Vis. Sci., 52: 1320-4, 2010.

8- WHITACRE M.M., STEIN R.A. and HASSANEIN K.: The effect of corneal thickness on applanation tonometry. American Journal of Ophthalmology, 115 (5): 592-6, 1993.

9- WU R.Y., ZHENG Y.F., WONG Y.Y., CHEUNG C.Y.C., LOON S.C., CHAUHAN B.C. and AUNG T.: Relationship of central corneal thickness with optic disc parameters: The Singapore Malay Eye Study. Inv. Ophthalmol. Vis. Sci., 52: 1320-4, 2010.

10- PALLIKARIS I.G., KYMIONIS G.D. and ASTYRAKAKIS N.I.: Corneal ectasia induced by laser in situ keratomileusis. J. Cataract. Refract. Surg., 27: 1796-802, 2001.

11- REINSTEIN D.Z., GOBBE M., ARCHER T.J., et al.: Epithelial, stromal, and total corneal thickness in keratoconus: Three-dimensional display with Artemis very-high frequency digital ultrasound. J. Refract. Surg., 26: 259$71,2010$. 
12- WANG J., FONN D., SIMPSON T.L., SORBARA L., KORT R. and JONES L.: Topographical thickness of the epithelium and total cornea after overnight wear of reversegeometry rigid contact lenses for myopia reduction. Invest. Ophthalmol. Vis. Sci., 44: 4742-6, 2003.

13- RUSKELL G.L. and BERGMANSON J.P.G.: Anatomy and physiology of the cornea and related structures. In: Phillip AJ, Speedwell L, eds. Contact Lenses. 5 th Ed. Oxford: ButterworthHeinemann, 2006.

14- VEYS J., MEYLER J. and DAVIES I.: Essential contact lens practice, 1 st Ed. Edinburgh: Butterworth-Heinemann, 2002.

15- BENE P., SYNEK S. and PETROVÁ S.: Corneal shape and eccentricity in population. Coll. Antropol., 37: 11720, 2013.

16- VOLLMER L., SOWKA J., PIZZIMENTI J. and YU X.: Central corneal thickness measurements obtained with anterior segment spectral domain optical coherence tomography compared to ultrasound pachymetry in healthy subjects. Optometry, 83 (5): 167-72, 2012.

17- HOFFMANN E.M., LAMPARTER J., MIRSHAHI A., et al.: Distribution of central corneal thickness and its association with ocular parameters in a large central european cohort: The gutenberg health study. PLoS ONE, 8 (8), 2013.

18- FRANCIS B.A., HSIEH A., LAI M.Y., et al.: Effects of corneal thickness, corneal curvature, and intraocular pressure level on goldmann applanation tonometry and dynamic contour tonometry. Ophthalmology, 114 (1): 206, 2007.

19- ZHANG H., XU L., CHEN C. and JONAS J.B.: Central corneal thickness in adult Chinese. Association with ocular and general parameters. The Beijing Eye Study. Graefes Arch. Clin. Exp. Ophthalmol., 246 (4): 587-92, 2008.

20- CHEN M.J., LIU Y.T., TSAI C.C., et al.: Relationship between central corneal thickness, refractive error, corneal curvature, anterior chamber depth and axial length. J. Chin. Med. Assoc., 72 (3): 133-7, 2009.

21- SU D.H., WONG T.Y., FOSTER P.J., et al.: Central corneal thickness and its associations with ocular and systemic factors: The Singapore Malay Eye Study. Am. J. Ophthalmol., 147 (4): 709-16, 2009.

22- CHANG S.W., TSAI I.L., HU F.R., et al.: The cornea in young myopic adults. Br. J. Ophthalmol., 85 (8): 961-70, 2001.

23- FAM H.B., HOW A.C., BASKARAN M., LIM K.Y., et al.: Central corneal thickness and its relationship to myopia in Chinese adults. Br. J. Ophthalmol., 90 (12): 1451-3, 2006.

24- SUZUKI S., SUZUKI Y., IWASE A., et al.: Corneal thickness in an ophthalmologically normal Japanese population. Ophthalmology, 112 (8): 1327-36, 2005.

25- IYAMU E. and EZE N.M.: The relationship between central corneal thickness and corneal curvature in adult Nigerians. S. Afr. Optom., 70: 44-50, 2011.

26- SAWADA A., TOMIDOKORO A., ARAIE M., IWASE A. and YAMATO T.: Refractive errors in an elderly
Japanese population: The infection after LASIK. Ophthalmology., 110: 276-85, 2003.

27- WOLFS R.C.W., KLAVER C.C.W., VINGERLING J.R., GROBBEE D.E., HOFMAN A. and De JONG P.T.V.M.: Distribution of central corneal thickness and its association with intraocular pressure: The Rotterdam study. American Journal of Ophthalmology, 123 (6): 767-72, 1997.

28- EYSTEINSSON T., JONASSON F., SASAKI H., et al.: Central corneal thickness, radius of the corneal curvature and intraocular pressure in normal subjects using noncontact techniques: Reykjavik Eye Study. Acta Ophthalmologica Scandinavica, 80 (1): 11-5, 2002.

29- CHUA J., THAM Y.C., LIAO J., et al.: Ethnic differences of intraocular pressure and central corneal thickness: The Singapore epidemiology of eye diseases study. Ophthalmology, 121 (10): 2013-22, 2014.

30- DURKIN S.R., TAN E.W.H., CAS SON R.J., SELVA D. and NEWLAND H.S.: Central corneal thickness among Aboriginal people attending eye clinics in remote South Australia. Clin. Exp. Ophthalmol., 35: 728-32, 2007.

31- AGHAIAN E., CHOE J.E., LIN S. and STAMPER R.L. Central corneal thickness of Caucasians, Chinese, Hispanics, Filipinos, African Americans, and Japanese in a glaucoma clinic. Ophthalmology, 11: 2211-9, 2004.

32- SHIMMYO M., ROSS A.J., MOY A. and MOSTAFAVI R.: Intraocular pressure, Goldmann applanation tension, corneal thickness, and corneal curvature in Caucasians, Asians, Hispanics, and African Americans. Am. J. Ophthalmol., 136: 603-13, 2003.

33- HAHN S., AZEN S., YING-LAI M. and ROHIT V.: The Los Angeles Latino Eye Study Group. Central corneal thickness in Latinos. Inv. Ophthalmol. Vis. Sci., 44: 1508$12,2003$.

34- DMITRII S. MALTSEV, M.D., Ph.D.; ELENA V. KUDRYASHOVA, M.D., D.Sc.; ALEXEI N. KULIKOV, M.D., D.Sc.; and ARTEM Y.U. MAREICHEV, M.D.: Relationship Between Central Epithelial Thickness and Central Corneal Thickness in Healthy Eyes and Eyes After Laser In Situ Keratomileusis. Cornea, 2018.

35- WU Y. and WANG Y.: Detailed distribution of corneal epithelial thickness and correlated characteristics measured with SD-OCT in myopic eyes. J. Ophthalmol., 2017: 1018321, 2017.

36- TAO A. et al.: Topographic thickness of Bowman's layer determined by ultra-high resolution spectral domainoptical coherence tomography. Invest. Ophthalmol. Vis. Sci., 52: 3901-7, 2011.

37- FRANCOZ M., KARAMOKO I., BAUDOUIN C. and LABBÉ A.: Ocular surface epithelial thickness evaluation with spectral-domain optical coherence tomography. Invest. Ophthalmol. Vis. Sci., 52: 9116-23, 2011.

38- REINSTEIN D.Z., et al.: Epithelial thickness in the normal cornea: Three-dimensional display with Artemis very high-frequency digital ultrasound. J. Refract. Surg., 24: 571-81, 2008

39- GOH W.S.H. and LAM C.S.Y.: Changes in refractive trends and optical components of Hong Kong Chinese aged 19-39 years. Ophthal. Physiol. Opt., 14: 378-82, 1994. 
40- LAM C.S.Y., GOH W.S.H., TANG Y.K., TSUI K.K., WONG W.C. and MAN T.C.: Changes in refractive trends and optical components of Hong Kong Chinese aged over 40 years. Ophthal. Physiol. Opt., 14: 383-8, 1994.

41- OSUOBENI E.P.: Ocular components values and their intercorrelations in Saudi Arabians. Ophthal. Physiol. Opt., 19: 489-97, 1999.

42- HOSNY M., ALIO M.J., CLARAMOINTE P., ATTIA W.H. and PEREZ SANTONJA J.J.: Relationship between anterior chamber depth, refractive state, corneal diameter, and axial length. J. Refract. Surg., 16: 336-40, 2000.

43- ORSSENGO G.J. and PYE D.C.: Determination of the true intraocular pressure and modulus of elasticity of the human cornea in vivo. Bull Math. Biol., 61: 551-72, 1999.

44- ROSA N., CENNAMO G., BREVE M.A. and La RANA A.: Goldmann applanation tonometry after myopic photorefractive keratectomy. Acta Ophthalmol. Scand., 76: 550-4, 1998.

45- TOMLINSON A.: A clinical study of the central and peripheral thickness and curvature of the human cornea. Acta. Ophthalmologica, 50 (1): 73-82, 1972.

46- MOHD-ALI B., AFZAMSHAH M.A.S., MOHAMMED Z. and MOHIDIN M.: Ocular dimensions of young Malays in Malaysia. J. Sains Kesihatan Malaysia, 9: 35-9, 2011.

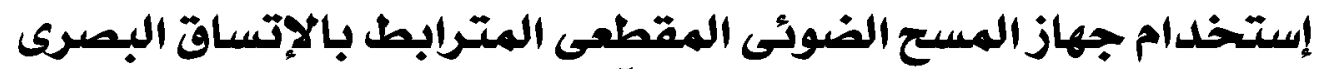

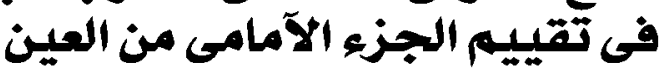

\author{
المقدمة: يعتبر جهاز التصوير المقطعى الطبقى هو تقنية بصرية غير ملامسة وآمنة تماما بلون آلم، لتصوير آدق تفاصيل العين الداخلية،

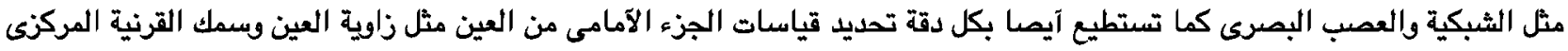

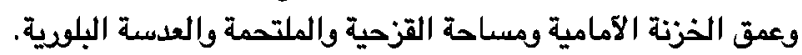

